\title{
IgG4 aortitis of the ascending thoracic aorta: A case report and literature review
}

\author{
Chaitanya Shilagani $^{1 *}$, Steven Lansman ${ }^{2}$, Anthony Gilet ${ }^{1}$, Milana Flusberg ${ }^{1}$ \\ 1. Department of Diagnostic Radiology, Westchester Medical Center, Valhalla, NY, USA \\ 2. Department of Cardiothoracic Surgery, Westchester Medical Center, Valhalla, NY, USA \\ * Correspondence: Chaitanya Shilagani, MD, Department of Diagnostic Radiology, Westchester Medical Center, Macy Pavilion, Suite \\ 1459, 100 Woods Rd, Valhalla, NY 10595, USA \\ $(-4$ Tanya.sc@gmail.com)
}

Radiology Case. 2021 May; 15(5):1-9 :: $\quad$ DOI: 10.3941/jrcr.v15i5.3985

\begin{abstract}
IgG4 aortitis is a recently recognized entity that can have clinical and imaging features that mimic acute aortic syndrome. Therefore, it is imperative for radiologists to be aware of how to potentially differentiate the two. Although this entity has been previously described via case reports and meta-analysis in the context of inflammatory abdominal aortic aneurysm, very few cases of ascending aortic involvement have been reported. In this case report, we present a case of a 60-year-old female transferred from another facility for an initial diagnosis of intramural hematoma of the ascending aorta and later found to have IgG4 aortitis post aortic root repair. This is a histologically confirmed case of multi-segmented IgG4 aortitis with rare involvement of both ascending and infra-renal aorta. We will briefly discuss the pathophysiology of IgG4 aortitis, along with review of literature.
\end{abstract}

\section{CASE REPORT}

\section{CASE REPORT}

A 60-year-old female was transferred from another facility for tertiary care with a diagnosis of intramural hematoma involving the ascending aorta. Her past medical history was significant for hypertension, hyperlipidemia, type II diabetes mellitus, hypothyroidism, obesity and history of deep venous thrombosis on Eliquis. Upon admission to our facility, the patient had stable vital signs with chief complaint of shortness of breath, cough, and congestion. She underwent an emergent computed tomography angiogram (CTA) of the thorax, abdomen and pelvis which demonstrated an ectatic ascending aorta measuring $4.7 \mathrm{~cm}$ (Fig. 1A), with the inner lumen measuring $3.3 \mathrm{~cm}$ (Fig. 1B). In addition, the noncontrast CT thorax (Fig. 2A) and the post contrast CTA thorax (Fig. 2B) demonstrated concentric wall thickening of the ascending aorta with adjacent fat stranding. There was an additional area of involvement of the infrarenal aorta and proximal right common iliac artery with similar imaging characteristics as the ascending aorta (Fig. 3A-C). No crescentic hyperdensity was seen in the involved aortic segment on non-contrast images (Fig. 4). A post processed 3D reconstruction of the aorta demonstrates soft tissue thickening surrounding the ascending aorta and infrarenal aorta (Fig. 5).

A cardiac catheterization did not reveal obstructive coronary artery disease. Due to her acute presentation and concern for rupture of the ascending aortic aneurysm, patient underwent median sternotomy for repair of the ascending aorta utilizing a hemiarch with Hemashield graft. Intraoperatively, the aortic root demonstrated concentric wall thickening with dense white fibrosis and adhesions (Fig.6AB). No intramural hematoma was seen. 
Patient was monitored for 5 days post-operatively and the hospital course was otherwise uneventful. A repeat CTA thorax, abdomen and pelvis revealed expected postoperative changes and the patient was later discharged for outpatient follow-up. The biopsy results of the ascending aorta later returned as Immunoglobulin G4 (IgG4) aortitis (Fig.7A-B). Patient's lab work at the time of admission indicated normal serum IgG4 level of $0.3 \%$ (normal range $0.0-0.5 \%$ ), and erythrocyte sedimentation rate of $13 \mathrm{~mm} / \mathrm{Hr}$ (normal range 0 30). There was mild elevation of C-reactive protein of 1.50 $\mathrm{mg} / \mathrm{dL}$ (normal range 0.00-0.50).

\section{DISCUSSION}

\section{Etiology \& Demographics:}

IgG4-related disease is a systemic condition that can have nonsynchronous or simultaneous involvement of multiple organs. IgG4-related sclerosing disease (IgG4-RSD) is a well described diagnosis involving autoimmune pancreatitis, in addition to involvement of salivary gland, thyroid, mediastinum, heart, kidneys and the retroperitoneum [1,2]. Few studies and case reports have described IgG4 related aortitis of the abdominal aorta, and even fewer case reports have been published on thoracic aortitis. IgG4 aortitis was first defined by Kasashima and colleagues in 2008 as a primary suspect in inflammatory abdominal aortic aneurysm (IAAA) [3].

\section{Clinical \& Imaging findings:}

Although the exact pathophysiology of $\mathrm{IgG} 4$ aortitis remains to be elucidated, Kasashima and colleagues (2018) proposed an inflammatory pathway that activates the $\mathrm{T}$ helper cells resulting in release of various cytokines, plasma cell infiltration and fibrosis [4]. The 'outside-in' theory suggests that the activated T-helper cells attract IgG4-positive B lymphocytes to the adventitia, which later differentiate into plasma cells [5]. The plasma cell infiltration of the adventitia can result in destruction of aortic wall elasticity and remodeling of the periadventitia via aggregation of cytokines and growth factors, eventually leading to a weakened wall that can predispose to aneurysm [4-6]. Risk of aneurysm increases when the inflammation extends to involve the media and lamellar elastic fibers [6,7].

On the gross specimen, the aorta demonstrates a bluish or whitish tinge superficially and is firm to palpation, which was seen in our patient upon initial incision (Fig. 6A) $[8,9]$. Histologically there is lymphoplasmacytic infiltration with storiform fibrosis as a dominant component, obliterative phlebitis, IgG4/IgG positive plasma cell ratio $\geq 40 \%$ and $\mathrm{IgG} 4$ positive plasma cell count $>10 / \mathrm{hpf}$ (high power field) as seen on immunohistochemistry [1-10]. On imaging, CTA demonstrates soft tissue thickening of the outer aortic wall, which can occasionally be mistaken for acute aortic syndrome such as intramural hematoma due to its overlapping appearance $[1,4,10]$.

Diagnostic criteria suggested based on findings described for IAAA by Kasashima and colleagues (2018) may be extended to diagnose IgG4 aortitis due to similar pathophysiology. The criteria include (a) - hypertrophic lesion of the arterial wall on imaging findings, (b) - increased serum IgG4 (>135mg/dL) and (c) - histopathological findings as described earlier. It is a definitive diagnosis if all three criteria are present. It is semi-diagnostic if (a) and (c) are present and suspected if (a) and (b) are present [4].

Difficulty in performing a biopsy and obtaining a pathology specimen of the aorta due to its location can make the diagnosis of $\mathrm{IgG} 4$ aortitis challenging. However, the diagnosis can be made in the presence of multifocal or multiorgan involvement and elevated IgG4-levels, which is $>90 \%$ sensitive [4]. Based on our case, radiological findings such as aortic wall thickening with fat stranding and multifocal involvement may be helpful as a diagnostic feature. Aguirre and colleagues (2015) suggested involvement of other organs, elevated inflammatory markers and PET/CT may be helpful in diagnosis [6].

\section{Differential Diagnosis:}

The presentation and involvement of the ascending aorta can result in a diagnostic dilemma especially in the setting of nonspecific patient presentation. Differential diagnosis of circumferential aortic wall thickening includes intramural hematoma, non-infectious aortitis such as vasculitides, and infectious aortitis [1,10,11]. Intramural hematoma can present as circumferential or crescentic wall thickening, which may or may not be hyperdense on noncontrast CT depending on acuity [12]. Additionally, patients with intramural hematoma present with severe acute chest pain that may or may not radiate to the back, changes in blood pressure in the upper extremities, or acute aortic regurgitation [13].

On the other hand, lab values rather than patient presentation allow for an accurate diagnosis in cases of infectious or non-infectious aortitis [11]. Patients with vasculitis and infectious aortitis have abnormal laboratory findings such as elevated acute inflammatory or infectious markers, ESR, CRP and white blood cell (WBC) along with nonspecific systemic manifestations such as fever, and weakness [14]. Infection of the aorta is rare and can form in pre-existing atherosclerotic plaque, which is the most common cause of aortic wall thickening [11].

\section{Treatment \& Prognosis:}

Surgical versus medical management of $\operatorname{IgG} 4$ aortitis currently remains controversial due to lack of randomized clinical trials [10]. Several studies have stated that medical management with steroid therapy can improve aortitis both clinically and radiographically $[1-4,6,10]$. However, risk of persistent luminal dilatation and aneurysmal rupture remains high in a patient undergoing high-dose glucocorticoid therapy alone [2]. Other proposed treatments include immunosuppressive therapy with methotrexate and B-cell depletion therapy with Rituximab [2,6,10]. Surgical management with aortic graft repair has shown improved postoperative course. Some patients have undergone stent repair mitigating the need for adhesiolysis [4]. 


\section{Conclusion:}

Presence of multifocal disease and low-density concentric thickening of the aortic wall on non-contrast CT with associated fat stranding can be utilized as an ancillary finding to diagnose aortitis. It is imperative for a radiologist to recognize the signs of IgG4 aortitis and raise the possibility of inflammatory aortitis rather than an acute aortic syndrome. This will allow for appropriate work-up and management of aortitis.

\section{TEACHING POINT}

Imaging diagnosis of IgG4 aortitis can be challenging, especially in the absence of fitting clinical presentation or diagnosis, as in our patient who presented with normal IgG4 levels. However, it is the role of a radiologist to recognize the imaging characteristics of vasculitis/aortitis and to raise the possibility of an alternative diagnosis to expediate appropriate clinical management.

\section{REFERENCES}

1. Byeon K, Han J, Kim JS, et al. Immunoglobulin G4-related periaortitis mimicking an intramural hematoma. Ann Thorac Surg. 2011;92(4):1506-1508. PMID: 21958804.

2. Luís M, Brites L, Fernandes B, et al. The many faces of IgG4-related disease: report of a case with inaugural recurrent aortic aneurism ruptures and literature review. Rheumatol Int. 2018;38(8):1565-1570. PMID: 29754327.

3. Kasashima S, Zen Y, Kawashima A, Endo M, Matsumoto Y, Kasashima F. A new clinicopathological entity of IgG4related inflammatory abdominal aortic aneurysm. J Vasc Surg. 2009;49(5):1264-1271. PMID: 19217746.

4. Kasashima F, Kawakami K, Matsumoto Y, Endo M, Kasashima S, Kawashima A. IgG4-Related Arterial Disease. Ann Vasc Dis. 2018;11(1):72-77. PMID: 29682110.

5. Kajander H, Paavonen T, Valo T, Tarkka M, Mennander AA. Immunoglobulin G4-positive ascending thoracic aortitis may be prone to dissection. J Thorac Cardiovasc Surg. 2013;146(6):1449-1455. PMID: 23062412.

6. Aguirre V, Connolly C, Stuklis R. IgG4-Aortopathy: An Underappreciated Cause of Non-Infectious Thoracic Aortitis. Hear Lung Circ. 2017;26(11):e79-e81. PMID: 28511923.

7. $\mathrm{Xu} \mathrm{L,} \mathrm{Heath} \mathrm{J,} \mathrm{Burke} \mathrm{A.} \mathrm{Ascending} \mathrm{aortitis:} \mathrm{A}$ clinicopathological study of 21 cases in a series of 300 aortic repairs. Pathology. 2014;46(4):296-305. PMID:24798167.

8. Moore DW, Hansen NJ, DiMaio DJ, Harrison WL. The great imitator: IgG4 periaortitis masquerading as an acute aortic syndrome on computed tomographic angiography. Radiol Case Reports. 2016;11(4):287-291. PMID:27920845.
9. Colombier S, Ruchat P, Gronchi F, Prêtre R, Niclauss L. Surgical procedure in immunoglobulin G4-related ascending aortitis? Ann Thorac Surg. 2014;97(4):3-5. PMID:24694451.

10. Guler GB. IgG4-related aortitis mimicking intramural hematoma. Anatol J Cardiol. 2016:728-729. PMID: 27609436.

11. Restrepo CS, Ocazionez D, Suri R, Vargas D. Aortitis: Imaging Spectrum of the Infectious and Inflammatory Conditions of the Aorta. RadioGraphics. 2011;31:435-451. PMID: 21415189.

12. Gutschow SE, Walker CM, Martínez-Jiménez S, Rosadode-Christenson ML, Stowell J, Kunin JR. Emerging concepts in intramural hematoma imaging. Radiographics. 2016;36(3):660-674. PMID: 27163587.

13. Alomari IB, Hamirani YS, Madera G, Tabe C, Akhtar N, Raizada V. Aortic intramural hematoma and its complications. Circulation. 2014;129(6):711-716. PMID: 24515957.

14. Okazaki T, Shinagawa S, Mikage H. Vasculitis syndromediagnosis and therapy. J Gen Fam Med. 2017;18(2):72-78. PMID:29263994

15. Tunick PA, Krinsky GA, Lee VS, Kronzon I. Diagnostic imaging of thoracic aortic atherosclerosis. American Journal of Roentgenology. 2000;174(4):1119-1125. PMID: 10749263. 


\section{FIGURES}

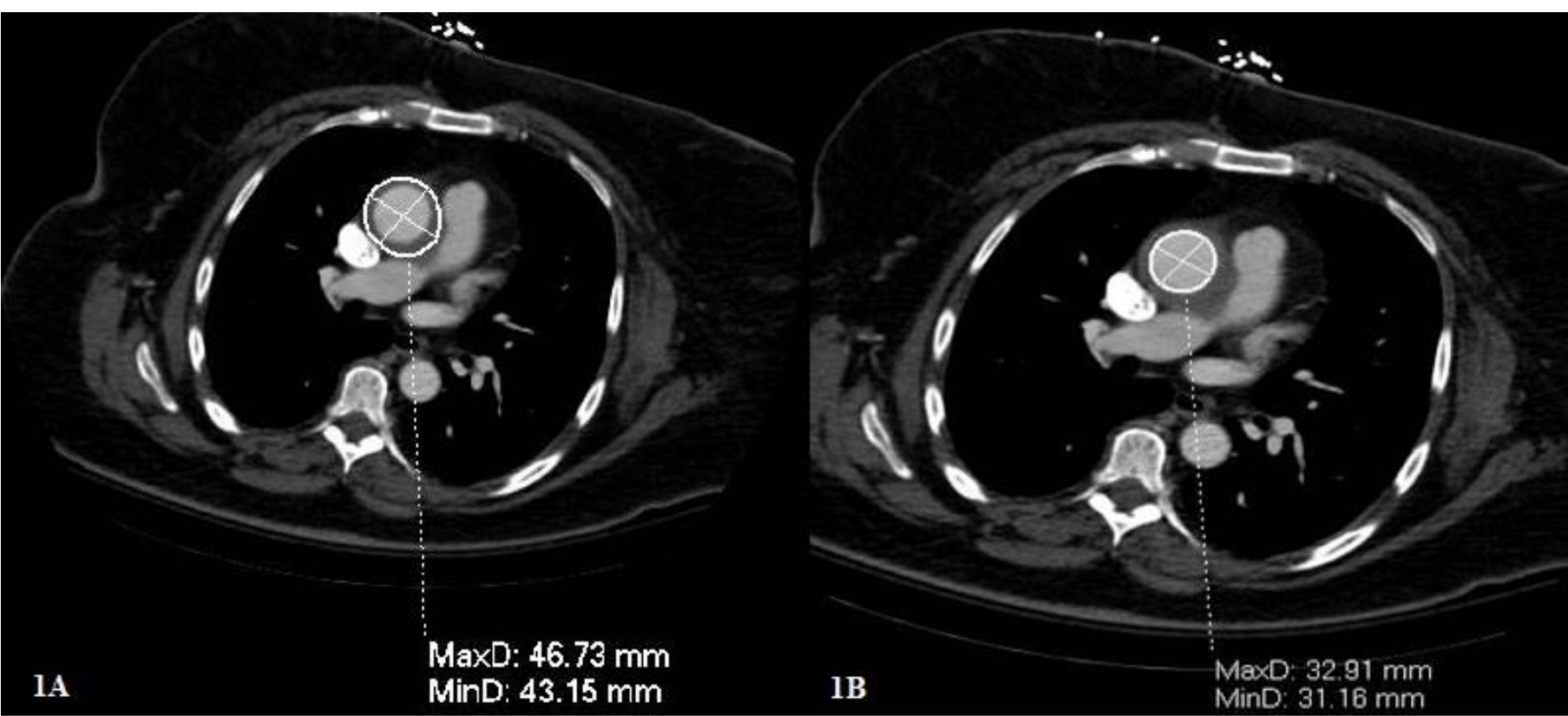

Figure 1: 60-year-old female with IgG4 aortitis.

FINDINGS: The axial CTA Thorax demonstrates ectatic ascending aortic measuring $4.7 \mathrm{~cm}(1 \mathrm{~A})$ although the inner lumen was within normal limits measuring $3.3 \mathrm{~cm}$ (1B).

TECHNIQUE: Helical axial angiographic images via Philips IQon Spectral CT of the thorax was obtained after uneventful

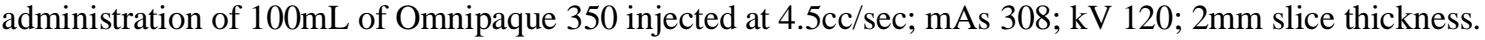

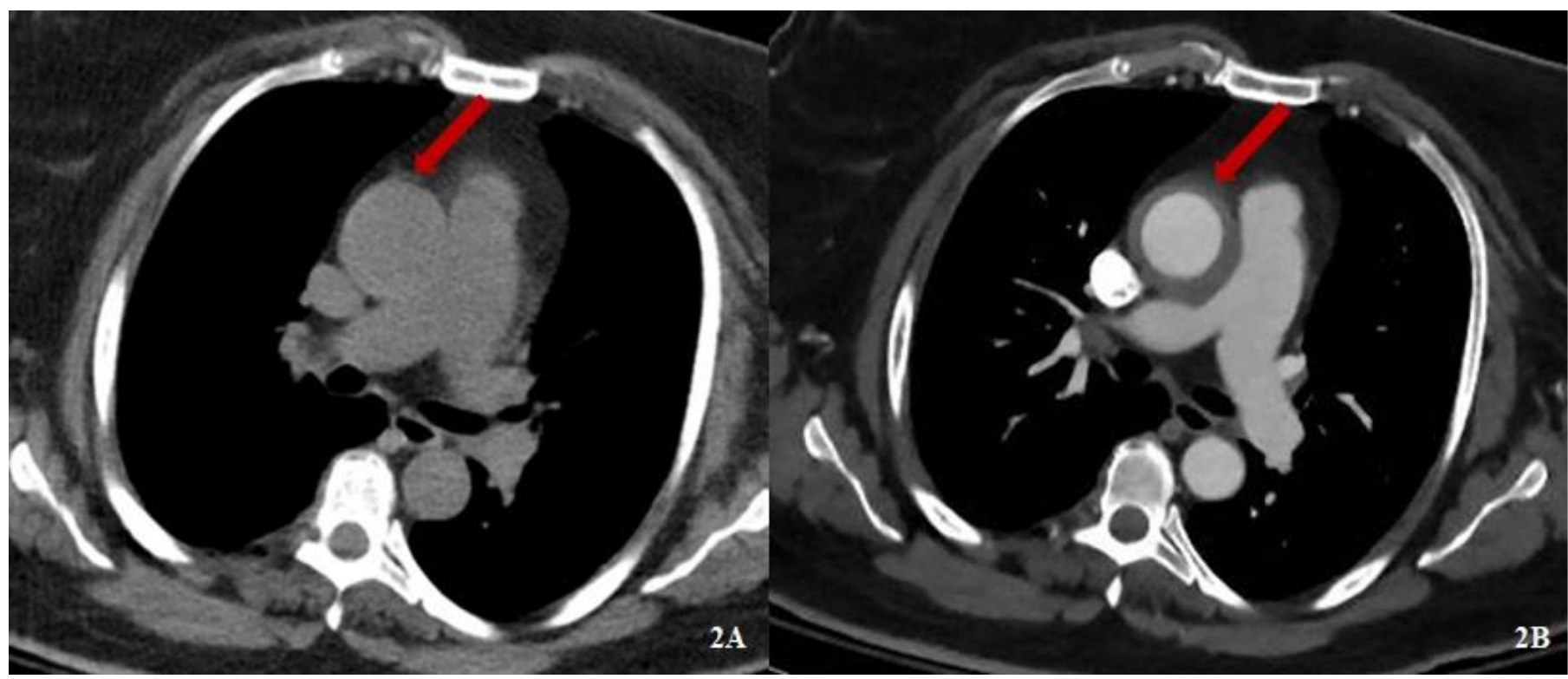

Figure 2: 60-year-old female with IgG4 aortitis.

FINDINGS: Axial pre-contrast CT Thorax (2A) and axial post-contrast CTA Thorax (2B) through the same level of the ascending aorta demonstrates circumferential soft tissue thickening with subtle adjacent fat stranding (red arrow).

TECHNIQUE: Helical axial angiographic images via Philips IQon Spectral CT of the thorax was obtained before and after

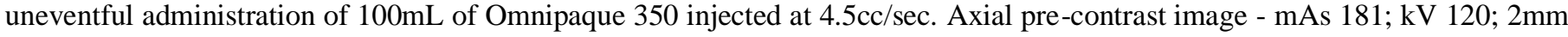
slice thickness. Axial post-contrast image - mAs 308; kV 120; 2mm slice thickness. 


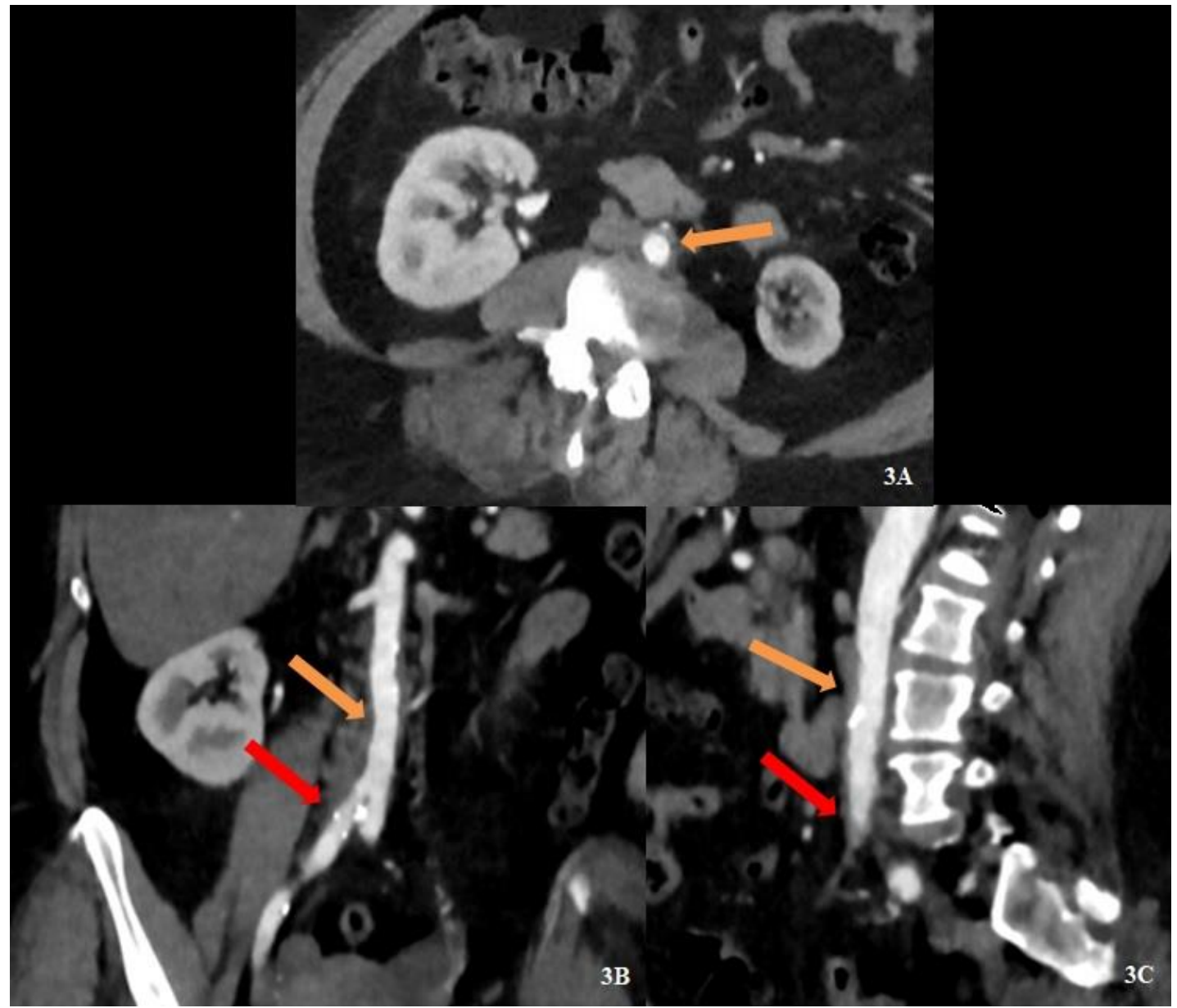

Figure 3: 60-year-old female with IgG4 aortitis.

FINDINGS: The axial (3A), coronal (3B) and sagittal (3C) CTA abdomen and pelvis demonstrates soft tissue density (orange block arrows - 3A, 3B and 3C) surrounding the infra-renal aorta. There is involvement of the proximal right common iliac artery (red block arrow - 3B and 3C).

TECHNIQUE: Helical axial angiographic images via Philips IQon Spectral CT of the abdomen and pelvis was obtained after

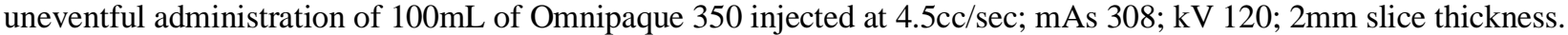

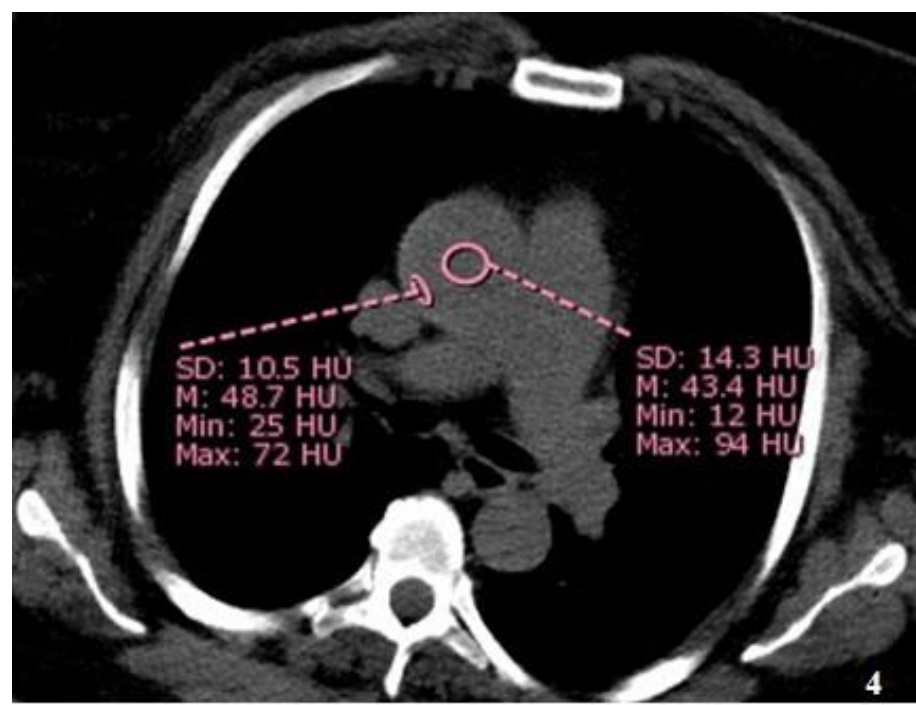

Figure 4 (left): 60-year-old female with IgG4 aortitis.

FINDINGS: Axial non-contrast CT thorax demonstrates similar Hounsfield units within the aortic lumen and along the periphery, in the region of the thickened aortic wall.

TECHNIQUE: Helical nonenhanced axial image via Philips IQon Spectral CT of the thorax was obtained; mAs 181; kV 120; $2 \mathrm{~mm}$ slice thickness. 


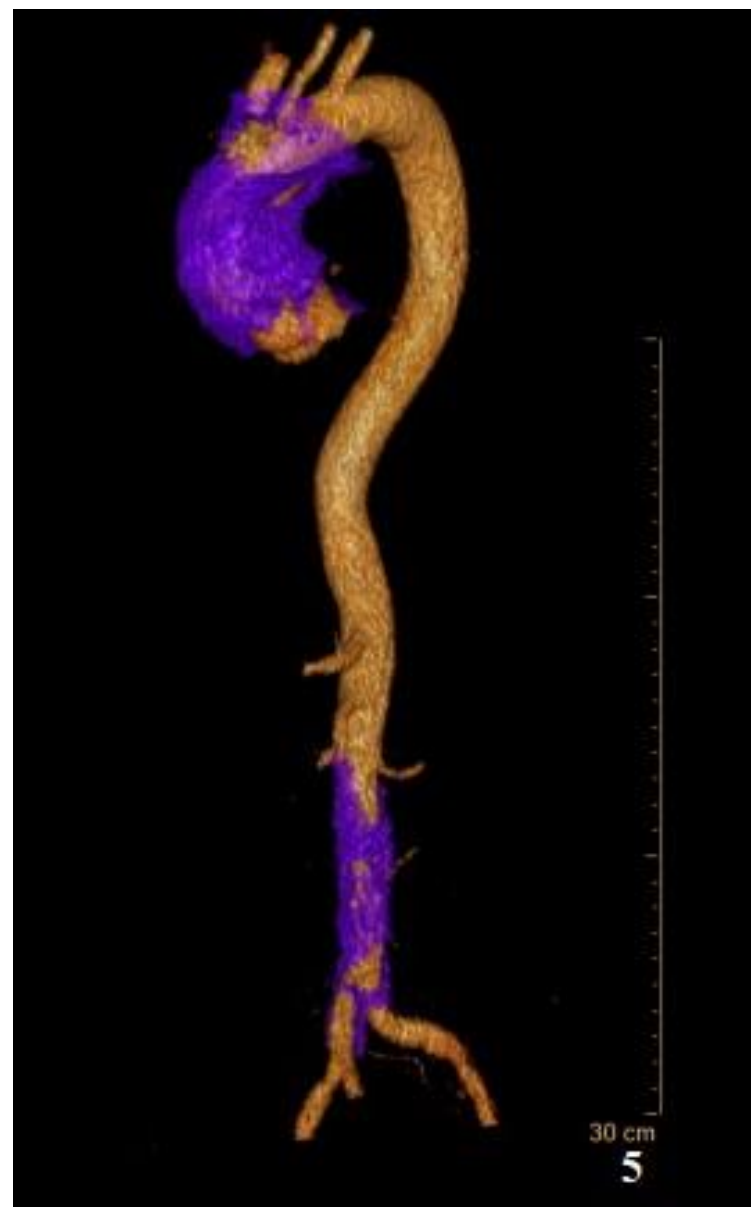

Figure 5 (left): 60-year-old female with IgG4 Aortitis.

FINDINGS: The reconstruction demonstrates soft tissue thickening (purple) surrounding the aortic root and the infrarenal aorta.

TECHNIQUE: Volumetric reconstruction of the aorta utilizing Philips Intellispace portal - AVA software was used to postprocess the contrast enhanced aorta.



Figure 6: 60-year-old female with IgG4 aortitis.

FINDINGS: Concentric thickening and dense white fibrosis of the aortic arch (red block arrow with blue outline - 6A and 6B). The intima was preserved (yellow block arrow with blue outline - 6B) without evidence of an intramural hematoma.

TECHNIQUE: Intraoperative photographs of the aortic arch. 


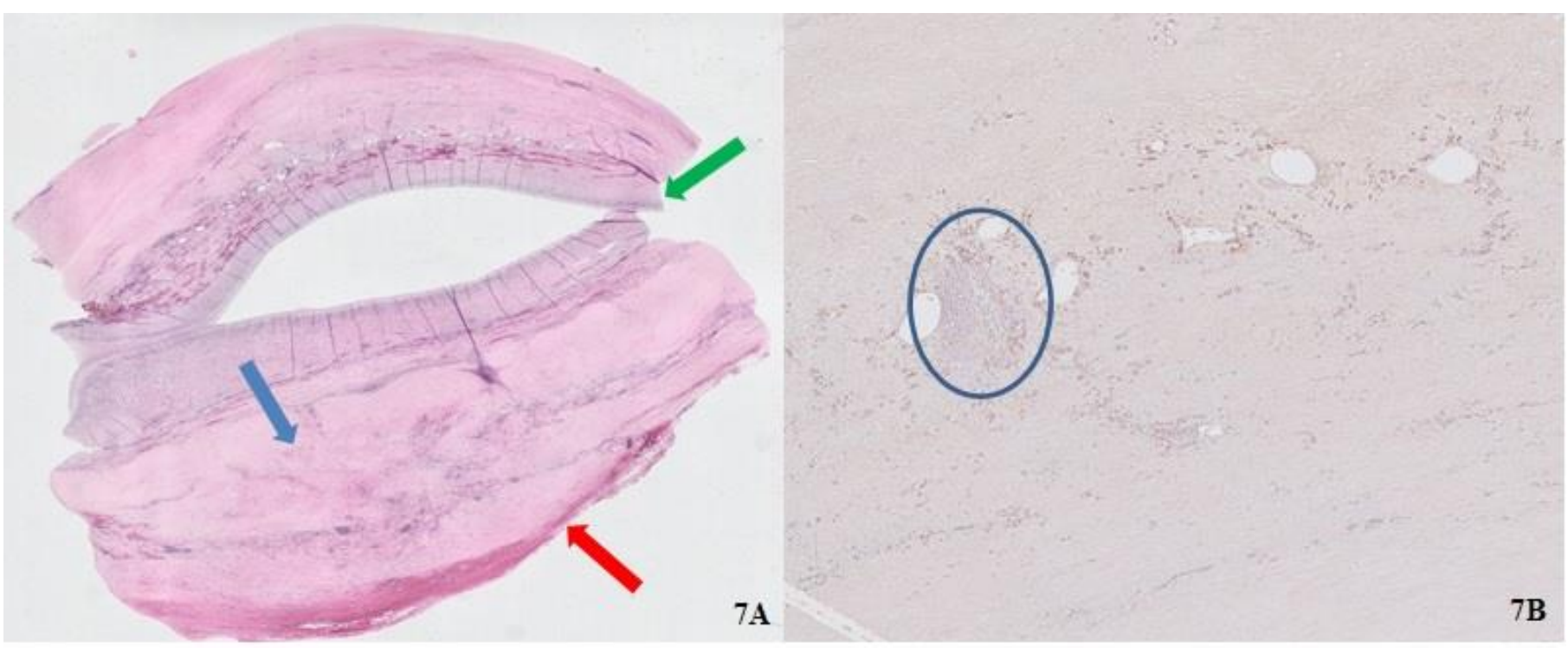

Figure 7: 60-year-old female with IgG4 Aortitis.

FINDINGS: Low power field (7A) transversely cut surface of the aorta demonstrates circumferentially thickened adventitia (red block arrow) with fibrotic media (blue block arrow), and preserved intima (green block arrow). High power field (7B) image of the adventitia demonstrates fibrosis and lymphoplasmacytic infiltration surrounding the vasa vasorum (blue circle).

TECHNIQUE: Immunostains for IgG and IgG4.

\begin{tabular}{|c|c|}
\hline Etiology & Unknown \\
\hline Incidence & - The exact incidence of IgG4 related thoracic aortitis is unknown due to its rarity. \\
\hline Gender Ratio & - Male > female \\
\hline Age predilection & - Elderly male; younger female \\
\hline Risk factors & - No known risk factors. Genetic research has shown certain HLA alleles can increase susceptibility. \\
\hline Treatment & $\begin{array}{l}\text { - Controversial - None of the suggested therapies have been supported by randomized clinical trials. } \\
\text { - Lesions can resolve spontaneously, especially in asymptomatic patients. } \\
\text { - Few patients require medical management with steroids or immunosuppressive drugs such as } \\
\text { methotrexate, azathioprine, mycophenolate mofetil, tacrolimus or rituximab. } \\
\text { - Treatment with surgery and graft repair in cases with IgG4 aortitis aneurysm due to increased risk of } \\
\text { rupture. }\end{array}$ \\
\hline Prognosis & $\begin{array}{l}\text { - Luminal dilatation with subsequent rupture - few cases treated with high-dose corticosteroids. } \\
\text { - Rituximab - Improvement in both clinical and radiological appearance of aortitis. } \\
\text { - Favorable outcomes have been seen in patients with graft repair. }\end{array}$ \\
\hline $\begin{array}{l}\text { Findings on } \\
\text { imaging }\end{array}$ & $\begin{array}{l}\text { - Circumferential thickening of the aorta seen in all cases on CT. } \\
\text { - FDG-PET - high sensitivity and uptake that correlates with disease activity. }\end{array}$ \\
\hline
\end{tabular}

Table 1: Summary table of IgG4 Aortitis. 


\begin{tabular}{|c|c|c|c|c|}
\hline $\begin{array}{l}\text { Differential } \\
\text { diagnosis }\end{array}$ & $\begin{array}{l}\text { Transesophageal } \\
\text { echocardiogram (TEE) }\end{array}$ & $\begin{array}{l}\text { Computed Tomography } \\
\text { (CT) }\end{array}$ & $\begin{array}{l}\text { Magnetic Resonance } \\
\text { Imaging (MRI) }\end{array}$ & $\begin{array}{l}\text { Fluorodeoxyglucose- } \\
\text { Positron Emission } \\
\text { Tomography (FDG- } \\
\text { PET) }\end{array}$ \\
\hline Atherosclerosis & $\begin{array}{l}\text { - Intimal thickening } \\
\text { with areas of } \\
\text { ulceration, } \\
\text { calcification, or } \\
\text { fibrous cap. }\end{array}$ & $\begin{array}{l}\text { Eccentric wall } \\
\text { thickening with a low- } \\
\text { density atheromatous } \\
\text { plaque that may or may } \\
\text { not be calcified. }\end{array}$ & $\begin{array}{l}\text { - MRI demonstrates } \\
\text { eccentrically located T1 } \\
\text { and T2 hypointense } \\
\text { plaque along the aortic } \\
\text { wall. } \\
\text { - MR angiography better } \\
\text { defines the aortic wall } \\
\text { and outlines the plaque. }\end{array}$ & - Rarely used \\
\hline $\begin{array}{l}\text { Intramural } \\
\text { hematoma } \\
\text { (IMH) }\end{array}$ & - Rarely used & $\begin{array}{l}\text { - Considered the } \\
\text { diagnostic modality of } \\
\text { choice due to its rapid } \\
\text { scan time in an } \\
\text { emergent setting. } \\
\text { - Demonstrates crescentic } \\
\text { aortic wall } \\
\text { hyperattenuation best } \\
\text { seen on nonenhanced } \\
\text { sequence. } \\
\text { - Subacute IMH may be } \\
\text { isoattenuating. } \\
\text { - CTA demonstrates } \\
\text { decreased luminal } \\
\text { diameter with a non- } \\
\text { enhancing eccentric } \\
\text { wall thickening. }\end{array}$ & $\begin{array}{l}\text { - Rarely used on initial } \\
\text { scanning. } \\
\text { - MRI can play a role in } \\
\text { follow-up imaging post } \\
\text { stent repair of acute } \\
\text { aortic syndrome. }\end{array}$ & - Rarely used \\
\hline $\begin{array}{l}\text { Vasculitis or } \\
\text { Aortitis }\end{array}$ & - Rarely used & $\begin{array}{l}\text { - Concentric vessel wall } \\
\text { thickening. } \\
\text { - Vessel wall } \\
\text { calcifications - seen in } \\
\text { chronic inflammation. } \\
\text { CTA can demonstrate } \\
\text { thrombosis, stenosis, } \\
\text { occlusion, or aneurysm. }\end{array}$ & $\begin{array}{l}\text { - MRI can demonstrate } \\
\text { early wall thickening } \\
\text { and edema on T2 } \\
\text { weighted imaging. } \\
\text { - Contrast enhanced MRI } \\
\text { can demonstrate } \\
\text { enhancement of the } \\
\text { thickened wall. } \\
\text { - MRA findings can } \\
\text { demonstrate } \\
\text { thrombosis, stenosis, or } \\
\text { occlusion. } \\
\end{array}$ & $\begin{array}{l}\text { - PET demonstrates } \\
\text { increased sensitivity } \\
\text { for extra-aortic } \\
\text { inflammation. } \\
\text { - FDG uptake usually } \\
\text { correlates with } \\
\text { disease activity. }\end{array}$ \\
\hline Infection & - Rarely used & $\begin{array}{l}\text { - Considered the } \\
\text { diagnostic modality of } \\
\text { choice. } \\
\text { - CT appearance of } \\
\text { infectious aortitis can } \\
\text { vary: arterial wall } \\
\text { thickening, periaortic } \\
\text { fluid collection, soft- } \\
\text { tissue accumulation, } \\
\text { rapidly increasing } \\
\text { aneurysm or } \\
\text { pseudoaneurysm and } \\
\text { occasionally air. }\end{array}$ & - Rarely used & - Rarely used \\
\hline
\end{tabular}

Table 2: Differential diagnosis table for IgG4 Aortitis. 


\section{ABBREVIATIONS}

$\mathrm{CRP}=\mathrm{C}$-reactive protein

$\mathrm{CT}=$ Computed Tomography

$\mathrm{CTA}=$ Computed tomography angiogram

$\mathrm{ESR}=$ erythrocyte sedimentation rate

FDG-PET = Fluorodeoxyglucose-positron emission tomography

IAAA = Inflammatory abdominal aortic aneurysm

IgG4 = Immunoglobulin G4

IgG4-RSD = Immunoglobulin G4-Related sclerosing disease

$\mathrm{IMH}=$ Intramural hematoma

MRA = Magnetic Resonance Angiography

MRI = Magnetic Resonance Imaging

$\mathrm{PET} / \mathrm{CT}=$ Positron emission tomography/Computed

Tomography

TEE $=$ Transesophageal echocardiogram

$\mathrm{WBC}=$ White blood cell

\section{KEYWORDS}

Aortitis; IgG4; intramural hematoma; vasculitis

\section{ACKNOWLEDGMENTS}

John Fallon, MD. Department of Pathology, Westchester Medical Center, Valhalla, NY

\section{Online access}

This publication is online available at:

www.radiologycases.com/index.php/radiologycases/article/view/3985

\section{Peer discussion}

Discuss this manuscript in our protected discussion forum at: www.radiolopolis.com/forums/JRCR

\section{Interactivity}

This publication is available as an interactive article with scroll, window/level, magnify and more features.

Available online at www.RadiologyCases.com

\section{Published by EduRad}

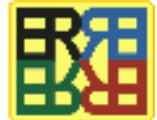

www.EduRad.org 